and concentrate antenatally on women with multiple partners and multiple pregnancies.

J Elizabeth Macgregor University Department of Pathology,
Aberdeen AB9 2ZD

\section{Psychosocial stress in pregnancy}

SIR,-I would like to thank Dr J Dearlove (8 September, p 613) and Dr M O Roland (22 September, $p$ 738) for their interest in our paper (18 August, p 411) and to answer their criticisms.

The women were interviewed three to four days after delivery to minimise the labile emotions associated with the time of delivery. It seems that it is those mothers going to term who have the better recall for those major life events considered to be subjective. We reviewed our results and divided the major life events into those considered to rely on subjective interpretation and those which were purely objective. The subjective life events represented $31 \%$ of the total recorded in the group going to term but only $19 \%$ of those recorded in the preterm groups combined.

The criticism of methodology is partially valid but there was overlap of interviewers, with two authors interviewing mothers from all three groups. The results from these interviews substantiated the trends seen in the whole sample.

I would emphasise again that few women had been asked about their worries during their pregnancies. I think it noteworthy that no one through your columns has supported our call for better "social" caring in what is probably a good caretaking antenatal service at a time when interest in place of birth is to the fore.

Booth Hall Children's Hospital,

RICHARD W NEWTON Manchester M9 2AA

\section{Appendicectomy and family history}

SIR,-The management of possible appendicitis, both at home and in hospital, is indeed influenced and complicated by the presence of past family histories of appendicitis or appendicectomy, as Dr N Andersson and his colleagues have suggested (22 September, p 697). Just over a decade ago I reported some findings from a study which was similar to theirs in intention. ${ }^{1}$

Two hundred and four females and 92 males (aged 12-29) who had had histologically inflamed appendices removed at emergency operations for acute abdominal pain were matched for age and sex with patients who had had histologically normal appendices removed at similar operations. All were sent a questionnaire asking how many of their parents and siblings had had their appendices removed. The relatives of female patients who had normal appendices removed included a significant excess with past appendicectomies $(\mathbf{P}<0.01)$ when compared with the relatives of those females with acute appendicitis. No such relationship was found with male patients.

These findings confirm that a past history of appendicectomy in the relatives of a patient with abdominal pain is of importance, but suggest that the importance is at least as likely to be behavioural as physical. Another reminder of the importance of behavioural influences on the management of acute abdominal pain which was reported in the paper was the excess number of normal appendices removed from the members of "medical" families. Dr Andersson's team should think again about how human factors influence the presentation and management of illness before they pursue the possibilities that their interesting findings might have either a dietary or a genetic basis. University Department of General Practice,
Aberdeen AB9 2AY

J G R HowIE

'Howie, J G R, Lancet, 1968, 1, 1365.

SIR,-The interesting article "Is appendicitis familial ?" by Dr N Andersson and others (22 September, p 697) prompts us to report an extraordinary coincidence in a pair of identical twins.

The first twin sister, aged $10 \frac{1}{2}$ years, presented in the afternoon of 24 February 1975 with a typical history of central abdominal pain radiating to the right iliac fossa. On examination there was guarding and tenderness with rebound tenderness. Emergency operation was undertaken in the early evening and an acutely inflamed appendix removed. The patient made an uneventful recovery and histology confirmed the diagnosis "fairly severe acute purulent non-obstructive appendicitis."

Later the same evening we saw the second child, who had been away at a different address and not in contact with her twin sister. She gave an identical history and also had signs of appendicitis with peritonitis. Emergency operation was undertaken the same evening and again an acutely inflamed appendix was removed. Histology confirmed the diagnosis of severe acute purulent appendicitisin this case due to obstruction by a small faecolith. The patient also made an uneventful recovery.

We are not aware of a previous report of acute appendicitis affecting identical twins at almost the same moment in time. It is interesting that in one twin a faecolith was present causing obstruction, but this was not so in the other twin.

London W1N $1 \mathrm{AH}$

Lionel GRacey STUART SANDERS

\section{Accidental injury in children and interrogation of families}

SIR,-In recent years there has been increasing pressure upon the profession to recognise cases of non-accidental injury to children. This is very laudable, but we wonder if anyone has actually looked into the effect on an accidentally injured child's family of the typical interrogation procedure to which relatives are now subjected.

A number of cases have recently come to our attention where great distress has been caused by the implied accusation which such questioning brings. Most parents, when under pressure, chastise their children from time to time; and current social mores concerning physical punishment of children lead to the formation of deep guilt feelings, which are easily aroused by injudicious accusations, real or imagined.

Many parents are insecure and uncertain anyway, especially those with known predisposing factors in their case histories, such as being young, having had children in special care units, multiple births, and abnormal children. While the doctor's primary aim is rightly to protect the child from non- accidental injury it must be remembered that this is achieved only by giving insecure families more support, and that the alienation achieved by what is perceived as a witch hunt is strongly counterproductive. Arguably, the deterioration in relations between parents and health service personnel we have observed may actually lead to more rather than less nonaccidental injury.

From these reflections we would like to ask one question and make two recommendations. (1) Has any research been undertaken into the type of interrogation we are considering, to determine its effects? (2) GPs, when referring injured children in whom they are sure that non-accidental injury is unlikely, should say so in their referral letter. (3) Hospital staff should be aware of the sensitive nature of their inquiries and should solicit the views of the GPs and health visitors who know the patients well before any form of confrontation.

J M ENGLISH P A SutLiefF

Hayes, Middx

\section{General practice in hospital accident and emergency departments}

SIR,-I refer to the article "Changes in demand for initial medical care in general practice and hospital accident and emergency departments" by Dr Joyce $M$ Watson and others (11 August, p 365) and the letter by Major P J Gravett (22 September, p 737).

Dr Watson's article implies that, contrary to the ethic of the GP consultative service, patients have a free choice of the two alternatives. Other than on this point, however, I agree with her comments. Her findings are supported by the Newcastle Accident Report. ${ }^{1}$ In themselves they do not disprove the contrary evidence of the Fourth Report from the Expenditure Committee, ${ }^{2}$ but it is reassuring to know that since this was prepared in 1973-4 the situation has not worsened-at least in Glasgow. I was pleased that she drew attention to the ratio of first attenders at accident and emergency departments and GP surgeries. Although her ratio is rather greater than that calculated from Fry's figures ${ }^{3}$ it does emphasise that failure of a general practitioner to provide emergency cover for one in every 100 of his patients leads to a $6-10 \%$ increase in casualty attendances, depending on the number of general practitioners and hospitals in the district.

I would, however, take issue with Major Gravett. He appears to have used Durbin's criteria for appropriate attendance at the accident and emergency department, ${ }^{4}$ although here I would have liked more information. Casualty departments do not treat only trauma-though there are many who, for the sake of a structured organisation, administrative convenience, or even clarity of exposition, would wish that they did. Their function must be seen in social rather than medical terms and it has not changed much since the mediaeval hospice served those displaced and disabled people who were suddenly rendered dependent on their immediate and perhaps estranged neighbour for help.

The spectrum of diagnoses of bona fide attenders is neither all accidents nor all emergencies-nor, in a medical sense, entirely composed of both. Almost all diagnoses can, in some circumstance, be disabling and render a person immediately community-dependent ${ }^{56}$ 